\title{
O QUE ESPERAM DE NÓS? DAS EXPECTATIVAS INDIVUDUALIZANTES ÀS PRÁTICAS ÉTICO-POLÍTICAS EM PSICOLOGIA ESCOLAR E EDUCACIONAL
}

\author{
¿QUÉ ESPERAN DE NOSOTROS? DE LAS EXPECTATIVAS INDIVUDUALIZANTES \\ A LAS PRÁCTICAS ÉTICO-POLÍTICAS EN PSICOLOGÍA ESCOLAR Y \\ EDUCACIONAL
}
WHAT DO THEY EXPECT OF US? FROM INDIVIDUALIZING EXPECTATIONS TO ETHICAL-POLITICAL PRACTICES IN SCHOOL AND EDUCATIONAL PSYCHOLOGY

\author{
Rogério Machado ROSA ${ }^{1}$ \\ Camila Rodrigues de Moraes CAMARGO ${ }^{2}$ \\ Luis Fernando ANDRADE ${ }^{3}$
}

RESUMO: O presente artigo foi desenvolvido a partir de uma experiência prática em Estágio Básico, vinculada ao componente curricular "Planejamento e Intervenções Socioeducacionais", em um curso de Psicologia. A intervenção, resultado do estudo teórico e metodológico sobre a produção de "bons encontros" (NOVIKOFF; CAVALCANTI, 2015) no que se refere à percepção do $\mathrm{Eu}$ e do Outro, ocorreu favorecendo os processos comunicacionais e de autopercepção em um grupo do $4^{\circ}$ Ano do Ensino Fundamental de uma Escola Pública. Discutimos neste artigo as expectitivas do trabalho dos psicólogos nas escolas, comumente associado a uma cultura institucional individualizadora, e os desafios da instauração de uma modalidade de atuação profissional tramada por princípios ético-estéticopolítico. Concluímos que o que se espera dos psicólogos na escola é a (re)produção de intervenções clínico-terapêutucas, voltadas para o ajuste, adaptação e normatização das crianças e seus processos de aprendizagem.

PALAVRAS-CHAVE: Psicologia escolar e educacional. Intervenção socioeducacional. Bons encontros.

RESUMEN: El presente artículo fue desarrollado a partir de una experiencia práctica en Etapa Básica, vinculada al componente curricular "Planificación e Intervenciones Socioeducativas", en un curso de Psicología. La intervención, resultado del estudio teórico y metodológico sobre la producción de "buenos encuentros" (NOVIKOFF; CAVALCANTI, 2015) en lo que se refiere a la percepción del Yo y del Otro, ocurrió favoreciendo los

${ }^{1}$ Universidade Federal de Santa Catarina (UFSC), Florianópolis - SC - Brasil. Centro de Ciências da Educação - CED. Docente. ORCID: https://orcid.org/0000-0002-8195-8303. E-mail: rogeriorosa.ufsc@gmail.com

${ }^{2}$ Universidade do Sul de Santa Catarina (UNISUL), Palhoça - SC - Brasil. Departamento de Psicologia. Estagiária de Psicologia. ORCID: https://orcid.org/0000-0003-3096-4137. camila.monitoriaunisul@gmail.com

${ }^{3}$ Universidade do Sul de Santa Catarina (UNISUL), Palhoça - SC - Brasil. Departamento de Psicologia. Estagiário de Psicologia. ORCID: https://orcid.org/0000-0001-8574-5316. E-mail: lfandrade1974@ hotmail.com 
procesos comunicacionales y de autopercepción en un grupo del $4^{o}$ Año de la Enseñanza Fundamental de una Escuela Pública. Discutimos en este artículo las expectitivas del trabajo de los psicólogos en las escuelas, comúnmente asociado a una cultura institucional individualizadora, y los desafíos de la instauración de una modalidad de actuación profesional tratada por principios ético-estético-político. Concluimos que lo que se espera de los psicólogos en la escuela es la (re) producción de intervenciones clínico-terapéuticas, orientadas al ajuste, adaptación y normatización de los niños y sus procesos de aprendizaje.

PALABRAS CLAVE: Psicología escolar y educacional. Intervención socioeducativa. Buenos encuentros.

ABSTRACT: The present article was developed based an experience in Basic Internship, connected to the curricular component "Socioeducational Planning and Interventions", in a Psychology course. The intervention, as a result of the theoretical and methodological study on the production of "good meetings" (NOVIKOFF; CAVALCANTI, 2015) regarding the perception of the Self and the Other, occurred favoring the communication and selfperception in a group of the 4th Year of the Elementary School of a Public School. We discuss in this article the expectations of the work of psychologists in schools - commonly associated with an individualizing institutional culture - and the challenges of establishing a modality profissional performance based on ethical-aesthetic and political principles. We conclude that what is expected of psychologists in school is the (re) production of clinical-therapeutic interventions, aimed at adjusting, adapting and normalizing children and their learning processes.

KEYWORDS: School and educational psychology. Socio-educational intervention. Good meeting.

\section{Apresentação}

O presente artigo foi desenvolvido a partir de uma experiência de intervenção alinhada aos pressupostos da Psicologia Escolar e Educacional. Trata-se de uma proposição interventiva tributária da Unidade de Aprendizagem" ${ }^{4}$ de "Planejamento e Intervenções Socioeducacionais", Componente Curricular de um Curso de Psicologia, que tem como objetivo fulcral Planejar, Executar e Avaliar Projetos de Intervenção em Contextos Socioeducacionais. Assim, o objetivo desse texto consiste em discutir as expectativas que sujeitos escolares possuem do trabalho dos psicólogos nas escolas; trabalho este comumente associado a uma cultura institucional individualizadora. Aqui, entretanto, apresenta-se em tipo de reflexão que investe no fomento e na instauração de uma modalidade de atuação

\footnotetext{
${ }^{4}$ Unidade de aprendizagem é o termo utilizado pela UNISUL - Universidade do Sul de Santa Catarina, para
} denominar "disciplina". 
profissional, no campo da Psicologia Escolar e Educacional, tranversalizada por princípios ético-estético-político.

Sabe-se que a presença da Psicologia e sua atuação no campo da educação possui uma longa história no Brasil. A Psicologia, como ciência autônoma, foi se construindo ao longo de vários séculos e, principalmente, ao longo do século XX. A ciência psicológica teve como papel nesta época, a adaptação do "chamado novo homem, que precisaria ser formado para assumir as tarefas impostas pelo desenvolvimento econômico, pela industrialização e pela modernização" (SOUZA et al., 2014, p. 124).

Com a institucionalização da profissão de psicólogo no Brasil, durante as décadas de sessenta e setenta do século passado, instaurou-se um modelo de Psicologia que podia ser chamado de "Psicologia 'do' escolar, aquela que se preocupava, especialmente com a identificação das características dos escolares" (SOUZA et al., 2014, p. 124). Essa proposta, portanto, tinha como principal preocupação, entre os pioneiros da Psicologia Educacional e Escolar, aqueles que não aprendiam, que não se alfabetizavam e que não aceitavam as regras escolares, modelo este ainda marcante nos contextos socioeducacionais contemporâneos.

A Ciência Psicológica aplicada à realidade escolar, com suas pesquisas e teorias psicológicas, procurava conhecer, a partir de uma relação causau, o desenvolvimento intelectual, afetivo e orgânico e suas relações com a constituição da personalidade dos sujeitos. Buscava-se conhecer para construir medidas de (a)normalidade relativas ao desenvolviemnto e à aprendizagem humana. Tais medidas, particularmente aquelas que sugeriam problemas no processo de desenvolvimento, a rigor eram localizadas no "interior" dos sujeitos (visão psicologizante); ou "fora" dos sujeitos (visão sociologizante), com origens socioeconômicas e cuturais (SOUZA et al., 2014). Ainda de acordo com a autora, esse modelo de intervenção profissional, estava voltado, basicamente, para a utilização de procedimentos de testagem psicológica, pelo atendimento individualizado, pela produção de diagnósticos e pelo tratamento das crianças-problema ou crianças com dificuldades de aprendizagem.

A partir dos anos 1980, houve uma crítica ao modelo clínico de intervenção na Escola, a partir da produção e dos estudos de Maria Helena Souza Patto, autora do conceito de "fracasso escolar". A referida autora chama a atenção para a necessidade de construção de uma compreensão crítica e complexa sobre as crianças que não aprendem. Propõe uma visão política do fenômeno do fracasso escolar, despsicologizando-o e dessociologizando-o. Com isso inaugura um campo teórico/prático que reivindica a necessidade de inclusão de variáveis 
psicoeducativas, psicossociais, institucionaos e culturais para a análise dos denominado "problemas de apresndizagam".

Nesta perspectiva, o escopo da discussão fora voltado para os processos que constituem o aluno que fracassa, levando em consideração o fenômeno do mau rendimento escolar, originário de aspectos macroestruturais do sistema capitalista, que estão articulados às políticas educacionais e no cotidiano escolar. Conforme Souza et al. (2014), com essas críticas ao modelo de intervenção da Psicologia no âmbito da educação passou-se a questionar a Psicologia, enquanto ciência, e seu função na difusão do conhecimento inviezados por pressupostos morais, autoritários, segregadores e entidemocráticos; e que dariam sustentação à reprodução da ideologia dominante.

Com essa crítica, iniciou-se um processo ruptura e/ou deslocamento epistemológico entre o modelo no qual os procedimentos de testagem acríticos vigoram e a buscando por abarcar a complexidade das relações escolares, pautado em uma perspectiva ético-política. Um deslocamento analítico que aponta para produção social e institucional do fracasso escolar. Um movimento reump á desculpabilização do sujeito, portanto.

Cabe destacar que, de acordo com as Referências Técnicas para a atuação de Psicólogos (as) na Educação Básica, do Conselho Federal de Psicologia (2013), a Escola consiste em um espaço de socialização que tem como objetivo favorecer experiências e a produção de conhecimento, integrando crianças e jovens às principais e primeiras redes sociais imprescindíveis para sua formação intelectual, social e subjetiva. Dessa forma, compreende-se que é na Escola, e isso significa também dizer, nesse entrelaçamento entre escola e comunidade, que se deve construir e exercitar a consciência de uma cidadania ativa e participativa.

Por esse motivo, ainda segundo CFP (2013), não se pode compreender a Educação sem inseri-la no contexto das políticas econômicas, das políticas públicas e sociais que lhe dão suporte, isto é, deve-se atuar nos contextos socioeducacionais mediante a cuidadosa observação do contexto social, cultural, político e econômico dos sujeitos neles inseridos.

Os autores (NENEVE; SOUZA, 2006) pontuam que a participação da Psicologia na discussão das contradições e conflitos do sistema escolar é importante visto o momento em que se encontra a escola brasileira. A participação da Psicologia tem a contribuir para que se realizem ações na contramão de uma prática que forma gerações de crianças e jovens excluídos, por não se apropriarem ativamente do conhecimento socialmente produzido, e esta atuação poderá permear desde a intervenção psicoeducativa até as psicossociais. 
Em última análise, de acordo com CFP (2013), a finalidade da atuação dos psicólogos nos contextos escolares, deve ter como medida o compromisso com a luta por uma escola democrática, de qualidade, e que garanta os direitos de cidadania ativa as crianças, jovens e profissionais da Educação como um todo. Nesse sentido, esse compromisso ético e político abarca a construção de uma escola participativa, comunitária, que busca resolver os conflitos e contradições nela existentes através da implicação de todos os sujeitos que compõem esse espaço.

Nesse sentido, cabe a nós, psicólogos em formação, observar as bases históricas e epistemológicas nas quais a Psicologia como ciência se construiu e refazer, na prática da Psicologia Escolar, algumas atuações que não cabem mais no contexto atual, ou, quem sabe, nunca couberam em contexto algum. A afirmação de uma escola democrática, legitimadora das diferenças, produtora de inclusão social e que entenda o sujeito como multideterminado, apresenta-se como um compromisso a ser assumido pelos psicólogos escolares e educacionais.

Assim, encadeamos a escrita do presente artigo articulando com duas questões fulcrais. Primeira: O que esperam de nós? O que as instituições socioeducativas esperam da interface entre Psicologia e Educação? Segunda: Qual a importância de uma política afetiva e produção de "bons encontros" na construção experiências de liberdade? Por fim, paralelamente a tais questões, promoveremos, no corpo do texto, a reflexão sobre qual o lugar das experiências políticas e democráticas pautadas nos afetos e bons encontros para a qualificação dos processos formativos no campo da Psicologia Escolar e Educacional, bem como para a formação profissional em Psicologia.

\section{Percurso metodológico}

O presente artigo foi desenvolvido a partir de uma intervenção alinhada à Psicologia Socioeducacional, que se deu em uma Escola de Educação Básica localizada no Município de Florianópolis, com alunos do quarto ano do Ensino Fundamental, do período matutino.

De início, entrou-se em contato com a instituição interessada com o objetivo de verificar a possibilidade de intervenção socioeducacional naquele contexto. Em seguida, realizou-se a apresentação de um projeto geral de intervenção acompanhado de uma carta formal de apresentação, que foi lido e avaliado pelas (os) gestoras (es) da Escola, a fim de alinhar uma proposta geral entre os estagiários e a instituição de ensino. Concomitante ao contato com a instituição de ensino, o projeto geral de intervenção foi encaminhado à Gerência Regional de 
Educação da Grande Florianópolis para avaliação do projeto, para possibilitar que a intervenção fosse realizada e legitimada.

Findada essa etapa de apresentação, após o deferimento do projeto por parte da instituição, a intervenção foi iniciada. A primeira etapa consistiu em um período de aproximadamente seis horas de observação participante. Os estagiários adentraram-se no contexto socioeducacional juntamente com os alunos, professores, gestores e outros profissionais da escola. A inserção inicial deu-se no contexto de sala de aula, no refeitório, no pátio e na quadra de esporte durante os intervalos entre as aulas. $\mathrm{O}$ período da observação participante foi fracionado de acordo com a disponibilidade dos estagiários e comunidade escolar, em dois dias.

De acordo com Fernandes e Moreira (2013), a observação participante, de forma sintética, pode ser caracterizada pela promoção da interatividade entre o observador, os sujeitos observados e o contexto no qual eles estão inseridos. Nesse sentido, permite com que o observador se encontre com o "outro", exercitando constantemente o respeito à alteridade, uma vez que, fundamentalmente, pressupõe o convívio e o intercâmbio de experiências primordialmente através dos sentidos humanos: olhar, falar, sentir, vivenciar, experimentar (FERNANDES; MOREIRA, 2013).

Possibilitando o contato direto com os sujeitos, a observação participante torna-se, assim, uma estratégia potente para o estabelece relações orgânicas entre os sujeitos observados e os observadores. No caso deste relato de experiência, optou-se pelo uso de diários de campo, para efetivar a coleta e análise de informações e dados. O diário de campo, ainda de acordo com Fernandes e Moreira (2013), caracteriza-se pelo método no qual o pesquisador registra suas impressões sobre o cotidiano e as interações dos sujeitos observados.

Concluída a fase de observação, a proposta geral de intervenção foi então revisitada e redesenhada, a partir das demandas expressas pelos gestores, professores. E, também, a partir da análise dos dados coletados no processo de observação participante. Na sequência, construiu-se um projeto temático de intervenção que foi, em conjunto com a comunidade escolar, definido e apresentado. O foco temático eleito foi "A percepção do eu em relação ao outro: como construir relações de alteridade a partir da produção de bons encontros". Nesse sentido, a baliza que fundamentou a referente intervenção no contexto socioeducacional foi a noção de intervenção construída com os gestores, professores, alunos e comunidade escolar, em uma perspectiva ético- política. 
A intervenção direta com os alunos do quarto ano do período matutino se deu em uma carga horária de aproximadamente nove horas. A intervenção foi então fracionada em seis encontros, sendo que na última foi realizado um fechamento com o grupo, fundamentado e compartilhado na troca de experiências entre os estagiários e alunos.

Os encontros foram planejados de acordo com os dados obtidos nas observações participantes, a partir daquilo que foi visto, escutado e vivenciado pelos estagiários, bem como a partir da demanda explicitada pelas gestoras (es) da escola e professora. Faz-se importante ressaltar o processo dialógico a partir do qual se construiu o projeto de intervenção, buscando aproximar os eixos: estagiários em Psicologia, Escola, professores e alunos, alinhando as solicitações escolares e institucionais aos preceitos epistemológicos, éticos e políticos da Psicologia. De modo geral, os encontros alinharam-se a partir da temática geral: "A percepção do eu em relação ao outro: como construir relações legitimadoras da alteridade com base na produção de bons encontros". Como desdobramento do tema gerla, elegeu-se as seguintes temáticas específicas: "integração grupal”, "reconhecimento de si e do outro", "violência na Escola" e "processos comunicacionais".

Sobre os processos comunicacionais, Del Prette, Del Prette (1998) discutem, no campo do Treinamento das Habilidades Sociais, que o reconhecimento integral da dimensão social dos processos de desenvolvimento e da aprendizagem tem evidenciado o papel fundamental das interações sociais e dos processos comunicacionais na construção do conhecimento e da subjetividade. Por esse motivo, a comunicação eficaz nas organizações, instituições e espaços escolares se faz importante e fundamental, no tocante à escola, imprescindível para o processo de ensino aprendizagem.

Para viabilizar os processos comunicacionais, entretanto, se faz necessário identificar o lugar que Eu ocupo, e que o Outro ocupa, e para isso, segundo Freire (2011) exercita-se o conceito de ética explicado por Lévinas, o filósofo da alteridade. Tal autor concebe ética como antecedente à Ontologia, pois coloca-nos a visitação do Outro como premissa para a instauração da subjetividade humana: primeiro pela separação de Mim em relação ao Outro, e, depois pela substituição de Mim pelo Outro. Isso significa que se faz necessária uma identificação do Eu, para posterior ida do Eu na direção de sua exterioridade, isto é uma implicação do Eu pela vinda do Outro. Há, de acordo com Freire (2011), uma alteridade que não pode ser negada, e que nos intima a assumir uma responsabilidade para com todos os outros. Essa é a dimensão ética que se pretende exercitar: devo me identificar como sujeito, e a partir daí, separar-me do Outro e identificá-lo e reconhecê-lo como sujeito. 


\section{O que esperam de nós?}

Segundo Viana (2016), não há clareza, por parte da comunidade escolar, sobre o papel do psicólogo(a) no campo da Psicologia Escolar. Fica claro, com isso, articulando com as experiências vivenciadas no campo, que as demandas que a comunidade escolar, representada pelos educadores (as) e gestores (as), apresentam aos representantes do trabalho psi, está centralizada no aluno, na resolução de problemas individuais e no psicodiagnóstico. Seriam estes os desafios a serem enfrentados pelo psicólogo(a) atuantes no contexto socioeducacional, isto é, promover um trabalho ético, político e fomentador dos processos democráticos, na contramão de práticas individualizadas e psicopatologizadoras, que por vezes, representam as demandas escolares mais explícitas.

A partir disso, é importante assinalar que têm aumentado as literaturas que apontam o esgotamento do modelo clínico aplicado ao contexto educacional, importando a avaliação das demandas a partir de um ponto de vista sistêmico, produzindo reflexões a partir de novos modelos de intervenção (VIANA, 2016). Foi nesse sentido que a intervenção no contexto socioeducacional se delineou, propondo práticas Psicologia Escolar e Educacional pensadas de um ponto de vista complexo e sistêmico. Perspectiva esta que visa promover reflexões e práticas que vinculam a singularidade dos sujeitos, e seus processos psíquicos, como processos construídos na intensa relação com dimensões sociais, políticas, culturais e institucionais.

As dificuldades, encontradas no campo, correspondem a um sistema de ensino pautado em estratégias que, embora sejam funcionais até certo ponto, desconsideram a subjetividade dos sujeitos que constroem a comunidade escolar e ampliada. Assim, Viana (2016) argumenta que as intervenções psicológicas podem facilitar os processos educacionais através da mediação, considerando os processos de transformação pessoal e grupal que ocorre com os envolvidos nesta rede comunitária que é a Escola. Tais mediações teriam como finalidade o fortalecimento da afetividade humana e a afirmação dos processos democráticos na escola.

Como isso, e também para além disso, é possível entrelaçar o respeito às diversas subjetividades à promoção de afetos alegres, e, consequentemente, de "bons encontros"; conforme discutem Novikoff e Cavalcanti (2015). Para os autores, trata-se de estratégia política e pedagógica que contribui a instituição de uma Psicologia Escolar e Educacional crítica e articulada à realidade socio individual. Psicologia esta comprometida com a conscientização social e comunitária, enredando não somente os alunos nas práticas políticas e pedagógicas, mas também pais, professores, gestores e comunidade ampliada. Sendo, então, 
os afetos e bons encontros uma ferramenta potente para uma compreensão sistêmica e complexa sobre os processos educativos, focando a intervenção psicológica nas possibilidades de melhorar as condições de aprendizagem e desenvolvimento, as relações interpessoais e as relações políticas comunitárias.

Nas intervenções realizadas pelos autores do presente artigo, foi possível constatar uma visão ainda individualista dos fenômenos considerados "problemáticos" no âmbito escolar, como as dificuldades de aprendizagem e falta de respeito às regras institucionais. Tais "problemas", que neste artigo denominaremos de fenômenos político, foram apontados pela gestão escolar de forma individual. Ou seja, localizadas nos sujeitos: "alunos problema" em uma "sala de aula problema".

Assim, os dados obtidos no campo, demonstram que se espera do Psicólogo na escola um atendimento individualizado, ou, quando de forma grupal, que atenda necessidades institucionais com base na resolução desses fenômenos "problemas" individuais, ou grupais. Giongo e Oliveira-Menegotto (2010) contribuem sustentando que os psicólogos encontram dificuldades no trajeto contrário a uma Psicologia Escolar Clínica e Psicométrica, uma vez que já se produziram modificações na atuação do Psicólogo Escolar. Segundo as autoras, as instituições escolares parecem ter cristalizado a ideia de o psicólogo que tem como função consertar os alunos problema. Nessa perspectiva, as autoras discutem que o profissional se depara cotidianamente com uma contradição: o que deve fazer sob uma perspectiva éticopolítica, e o que é demandado fazer pela escola e contexto socioeducacional.

É nesse sentido que se discute a importância da produção de conhecimento, acerca de práticas psicológicas políticas e democráticas no contexto socioeducacional. Conhecimentos que subsidiem metodologias e práticas comprometidas com experiências libertadoras/desculpabilizadoras na escola, principalmente porque assumem sua natureza política e ética.

\section{Política afetiva e produção de "bons encontros" e experiências de liberdade}

Segundo Novikoff e Cavalcanti (2015), o que promove o conhecimento são os afetos. Para Spinoza, o termo afecção, ligado ao termo afeto, diz respeito à uma transformação promovida pelo encontro com outro corpo. Então, o que promove o conhecimento é o encontro de corpos. A educação, à luz do pensamento de Spinoza, se dá a partir do encontro de corpos que se afetam mutuamente. A educação ou a aprendizagem se dão a partir dos 
afetos, ou seja, é um processo vinculado à afetividade. Segundo Novikoff e Cavalcanti (2015), o estudante somente estuda e aprende quando encontra paixão ou vontade de estudar.

A aprendizagem, nesse contexto, está vinculada à ideia do bom encontro. Entende-se por bom encontro, segundo Novikoff e Cavalcanti (2015), como algo que possibilite um aumento da potência, isto é, da capacidade de um corpo ser afetado por outro corpo e ter as suas potencialidades de ação ampliadas. Portanto, no que diz respeito à relação entre professor e aluno, a política de produção de afetos alegres é fundamental para a instauração de bons encontros entre os sujeitos e também com os conhecimentos a serem aprendidos.

Pensando a partir da teoria dos afetos, a respeito da construção de espaços socioeducacionais políticos e democráticos, pode-se pensar a experiência de intervenção aqui relatada, particularmente no recorte das dinâmicas relacionais e comunicacionais da sala de aula, em uma configuração mais participativa e mais afetuosa. Buscou-se promover um tipo de reorganização da experiência na sala de aula na qual houvesse menos espaço para repreensões e mais espaço para relações mais afetuosas no grupo: professora, estagiários e alunos, havendo como consequência uma modificação efetiva do comportamento da classe, principalmente no que se refere ao respeito, alteridade e legitimação da presença do outro no grupo.

Nesse sentido, houve um investimento, por parte dos autores da intervenção, na construção de estilos de ralações pautadas no reconhecimento e legitimação da alteridade. Todas as atividades desenvolvidas com o coletivo de estudantes voltaram-se para essa finalidade. Tal perspectiva mostra-se fundamental no decorrer do trabalho, pois a experiência da democrático passa fundamentalmente pelo exercício e investimento cotidiano de uma ética da alteridade, isto é, o respeito radical às diferenças.

Também foi possível constatar que os alunos identificados pela gestão da escola como "problemáticos", ou os que apresentavam "comportamentos disfuncionais", do ponto de vista da educação tradicional; reivindicavam para si o direito à diferença. Por vezes essas manifestações eram interpretadas pelos professores e gestores como rebeldia. Contudo, mais parecia se tratar de um movimento de resistência à aos discursos e práticas pedagógicas autoritárias e estigmatizantes.

Nesse sentido, é importante resgatar uma intervenção realizada com os alunos, durante um conflito ocorrido após o recreio. Os alunos, ao chegarem em sala de aula após o intervalo entre aulas, discutiam uns com os outros, sem ouvir a opinião dos colegas. Naquele momento, os estagiários, sem entender o motivo do conflito, tentaram se conectar com a situação ocorrida e aos poucos tentar ouvir as diferentes versões das causas do conflito instaurado. 
Alguns alunos, que apresentavam comportamentos considerados inadequados para aquela situação coletiva, como gritar enquanto um colega falava e desrespeitar o outro com xingamentos. Notou-se nesta na situação narrada grande dificuldade de solucionar um conflito por meio do diálogo e da negociação. Havendo, portanto, certa reprodução, entre as crianças, de uma cultura autoritária, como ressonância da cultura institucional.

Percebeu-se que, de modo geral, o mediador, seja ele o estagiário, o professor ou gestor, na tentativa de ser ouvido, acaba por reiterar o padrão do sistema ali instaurado. Ao gritar e pedir silêncio até ser ouvido, uma espécie de ciclo vicioso de retroalimentação do autoritarismo antidemocrático ali se perpetuava. Muitas vezes utilizando-se de ameaças e trocas de favores para recuperar o controle da situação.

$\mathrm{Na}$ tentativa de proporcionar uma outra experiência afetuosa e democrática, e a fim de promover um bom encontro com o grupo, os estagiários se aproximavam dos alunos, e através do toque e de falas respeitosas, comunicavam que era importante que os alunos respeitassem a vez do outro falar, para que todos pudessem ser ouvidos. Foi combinado com os alunos que todos seriam ouvidos, e que para isso, precisariam da contribuição de todos. Durante a mediação do conflito, orientou-se aos alunos que pudessem, ao invés de acusar e gritar uns com os outros, pudessem falar para o colega como estavam se sentindo uns com os outros. Durante esse processo os estagiários puderam circular no espaço físico da sala de aula, promovendo falas e atitudes de afeto, com o objetivo de promover uma nova experiência coletivo/individual em sala de aula; diferente da que estava em vigor naquele contexto.

Percebeu-se, nos encontros posteriores, uma gradativa mudança de comportamento das crianças. Estendeu-se o investimento nesse clima dialógico, afetuoso, empático e ético para todos os encontros; com a finalidade de instauração de uma cultura democrática em sala de aula. Ao longo das semanas, percebeu-se, por parte dos alunos, sucessivos gestos de prestígio à presença e atitudes dos colegas, além de posturas mais respeitosas e altruístas. As relações professor-aluno, professor-estagiários, alunos- estagiários e alunos-alunos começaram a passar por um processo de transformação em termos de convivência cotidiana, particularmente no que se refere à substituição de comportamentos opressivos e hostis por experiência de cuidado, solidariedade e valorização do outro.

\section{Síntese reflexiva}

A intervenção socioeducacional realizada permitiu constatar, empiricamente, aquilo que as literaturas contemporâneas em Psicologia Educacional e Escolar têm demonstrado: a 
necessidade de realização de trabalhos que invistam na instauração e afirmação dos processos coletivos democráticos, éticos e estéticos nos contextos Socioeducacionais. Deslocando-se, com isso, dos pressupostos psicologizantes que responsabilizam o sujeito/grupo por seu fracasso, por sua inabilidade social e/ou cognitiva; desconsiderando os vetores institucionais, culturais e pedagógicos atuantes na produção e reprodução desses fenômenos.

Percebeu-se que o investimento na produção de afetos ativos e de bons encontros, discutidos por Novikoff e Cavalcanti (2015), contribuiu sobremaneira para a ampliação e transformação dos processos comunicacionais e afetivos no grupo, e na também relação grupo-professores-gestão. Foi possível visualizar, no grupo de crianças e também na relação criança-adultos, mudanças comportamentais relativas à resolução de conflito e qualificação da comunicação diária.

Trata-se de mudanças de estilos de relações: de autoritárias para dialógicas. Modos de com-vivência fundamentados em uma ética efetiva e em uma política de produção e de promoção de bons encontros. E que uma vez transformados em uma cultura, na sala de aula e também fora dela, podem instaurar uma cultura de participação, de sentimento de pertença e de co-responsabilização na produção o bem estar e garantia de direito à experiência democrática para todos e para cada um.

\section{REFERÊNCIAS}

\section{CONSELHO FEDERAL DE PSICOLOGIA. Referências técnicas para Atuação de Psicólogas(os) na Educação Básica. Brasília: CFP, 2013.}

DEL PRETTE, Z. A. P.; DEL PRETTE, A. Desenvolvimento Interpessoal e educação escolar: o enfoque das habilidades sociais. Temas em Psicologia, São Carlos, v. 6, n. 3, p. 205-215, 1998. Disponível em: http://betara.ufscar.br:8080/pesquisa/rihs/armazenagem/pdf/artigos/delprette-z.-a.-p.-del-prette-a.-1998-.-desenvolvimento-interpessoal-e-educacao-escolar-enfoquedas-habilidades-sociais/view. Acesso em: 4 dez. 2017.

FERNANDES, F. M. B.; MOREIRA, M. R. Considerações metodológicas sobre as possibilidades de aplicação da técnica de observação participante na Saúde Coletiva. Physis: Revista de Saúde Coletiva, v. 23, n. 2, p. 511-529, jun. 2013. FapUNIFESP (SciELO). DOI: http://dx.doi.org/10.1590/s0103-73312013000200010

FREIRE, P. Educação Como Prática da Liberdade. 34. ed. 2011.

GIONGO, C.; OLIVEIRA-MENEGOTTO, L. M. de. (Des) Enlaces da psicologia escolar na rede pública de ensino. Psicol. USP, São Paulo, v. 21, n. 4, p. 859-874, 2010. Disponível em: http://www.scielo.br/scielo.php?script=sci_arttext\&pid=S010365642010000400011\&lng=en\&nrm=iso. Acesso em: 25 apr. 2017. DOI: http://dx.doi.org/10.1590/S0103-65642010000400011. 
NOVIKOFF, C.; CAVALCANTI, M. A. de P. Pensar a potência dos afetos na e para a educação. Conjectura: Filos. Educ, Caxias do Sul, v. 20, n. 3, p. 88-107, set./dez. 2015. Disponível em:

http://www.ucs.br/etc/revistas/index.php/conjectura/article/viewFile/3442/pdf_450. Acesso em: 7 maio 2017.

SOUZA, M. P. R. de et al. Atuação do Psicólogo na Educação: análise de publicações científicas brasileiras. Psicologia da Educação, São Paulo, n. 38, p. 123-138, 2014. 1. Sem. Disponível em: http://pepsic.bvsalud.org/pdf/psie/n38/n38a11.pdf. Acesso em: 25 abr. 2017.

VIANA, M. N. Interfaces entre a Psicologia e a educação: reflexões sobre a atuação em Psicologia escolar. In: FRANCISCHINI, R.; VIANA, M. N. (org.). Psicologia Escolar: que fazer é esse?. Brasília: CFP, 2016. p. 54-70.

\section{Como referenciar este artigo}

ROSA, Rogério Machado; CAMARGO, Camila Rodrigues de Moraes; ANDRADE, Luis Fernando. O que esperam de nós? Das expectativas individualizantes às práticas éticopolíticas em psicologia escolar e educacional. Doxa: Rev. Bras. Psico. e Educ., Araraquara, v. $21, \quad$ n. $1, \quad$ p. 135-147, jan./jun. 2019. e-ISSN: 2594-8385. DOI: https://doi.org/10.30715/doxa.v21i1.12048

Submetido em: 20/10/2018

Revisões requeridas: $12 / 11 / 2018$

Aprovado em: $15 / 12 / 2018$

Publicado em: 01/02/2019 